\title{
CARACTERIZAÇÃO MORFOLÓGICA DAS PLÂNTULAS DE CINCO ESPÉCIES ARBÓREAS DA FLORESTA ESTACIONAL SEMIDECIDUAL, BRASIL
}

\author{
Aline Lopes ${ }^{1}$, Sonia Maciel da Rosa-Osman ${ }^{2}$, Maria Teresa Fernandez Piedade ${ }^{2}$ \\ ${ }^{1}$ Bióloga, M.Sc., INPA, Manaus, AM, Brasil - alopesmga@ gmail.com \\ ${ }^{2}$ Bióloga, Dr ${ }^{\mathrm{a}}$., INPA, Manaus, AM, Brasil - smrosa@inpa.gov.br; maitepp@inpa.gov.br \\ Recebido para publicação: 01/09/2010 - Aceito para publicação: 01/08/2011
}

\begin{abstract}
Resumo
As espécies arbóreas Astronium graveolens (Anacardiaceae), Cedrela fissilis (Meliaceae), Gallesia integrifolia (Phytolaccaceae), Parapiptadenia rigida (Fabaceae) e Tabebuia avellanedae (Bignoniaceae) ocorrem em remanescentes da Floresta Estacional Semidecidual do norte e noroeste paranaense e interior do estado de São Paulo. As plântulas dessas espécies foram descritas morfologicamente com o objetivo de subsidiar sua identificação em campo. As plântulas analisadas mostraram-se distintas desde suas folhas cotiledonares até os eófilos e metáfilos, podendo ser localizadas facilmente na comunidade vegetal. As folhas das cinco espécies são pecioladas e apenas $C$. fissilis e T. avellanedae apresentaram eófilos. Cedrela fissilis apresenta eófilos do tipo composto, trifoliado, com margem íntegra, e T. avellanedae, eófilos do tipo simples com margem serreada. As plântulas de G. integrifolia possuem metáfilos simples, e as de $C$. fissilis, $T$. avellanedae e A. graveolens têm metáfilos compostos, enquanto que nas plântulas de $P$. rigida os metáfilos são recompostos. Como as plântulas são visualmente distintas, a identificação em campo torna-se possível.

Palavras-chave: Astronium graveolens; Cedrela fissilis; Gallesia integrifólia; Parapiptadenia rígida; Tabebuia avellanedae.
\end{abstract}

\begin{abstract}
Morphological characterization of seedlings of five tree species from the tropical semideciduous forest, Brazil. The tree species Astronium graveolens (Anacardiaceae), Cedrela fissilis (Meliaceae), Gallesia integrifolia (Phytolaccaceae), Parapiptadenia rigida (Fabaceae) and Tabebuia avellanedae (Bignoniaceae) are found in remnants of tropical semideciduous forest in the North and Northwest of Paraná State and interior of the State of São Paulo. This study describes the morphological characteristics of seedlings in order to enable their identification in the field. Seedlings analyzed proved to be morphologically distinct from their cotyledons to eophylls and metaphylls and they may easily be distinguished in the plant community. All species showed leaves with petioles, and only $C$. fissilis and T. avellanedae presented eophylls. Cedrela fissilis has compounded eophyll, trifoliate, with integral edge, while in $T$. avellanedae it is simple, with serrated edge. Seedlings of $G$. integrifolia presented simple mesophyll, while the metaphyslls of $C$. fissilis, T. avellanedae and A. graveolens metaphylls are compounded ; in $P$. rigida the metaphyll is bipinate. Since seedlings were visually distinct, the field's identification is possible.
\end{abstract}

Keywords: Astronium graveolens; Cedrela fissilis; Gallesia integrifólia; Parapiptadenia rígida; Tabebuia avellanedae.

\section{INTRODUÇÃO}

As espécies arbóreas nativas têm sido objeto de grande interesse nos últimos anos, em função de sua importância na recomposição de ambientes alterados por várias formas e níveis de degradação. Ainda hoje é válido afirmar que pouco se conhece da biologia das espécies de ecossistemas florestais tropicais, sendo necessários estudos ecológicos, morfológicos, de biologia reprodutiva, entre outros, que auxiliem no sucesso de projetos de recuperação (BARBOSA et al., 2003). Os trabalhos sobre morfologia de plântulas em Floresta Estacional Semidecidual ainda são restritos, podendo ser citadas as investigações de 
Kuniyoshi (1983), Roderjan (1983), Souza e Moscheta (1992), Mourão et al. (2002), Souza e Oliveira (2004) e Cavichiolo (2006).

As sementes e as plântulas, quando consideradas em conjunto, podem revelar muito sobre a história ecológica e evolutiva de qualquer grupo de plantas (DUKE; POLHILL, 1981), e suas características podem ser úteis para a identificação de táxons, como salientado por Palácios e Bravo (1975) e Beltrati (1978). A fase inicial do desenvolvimento de diversas espécies vegetais é um período crítico em seu ciclo biológico (MIQUEL, 1987), podendo determinar e explicar a distribuição dos indivíduos adultos. Da mesma forma, o fracasso no processo adaptativo no estágio de plântula pode levar à extinção da espécie (AMO-RODRIGUES, 1979; GOMEZ-POMPA; WIECHERS, 1976), pois é esta a fase na qual os indivíduos mostram-se mais suscetíveis aos fatores condicionantes de um determinado ambiente (GARWOOD, 1996; MORAES; PAOLI, 1999). Após a fase de plântula, as espécies vegetais passam a depender diretamente do ambiente em que se estabeleceram, de acordo com as características morfológicas peculiares que desenvolveram (RESSEL et al., 2004).

A combinação de características da semente e do adulto, presentes nas plântulas, pode fornecer numerosos indícios para a identificação das espécies no campo e em amostras de sementes (DUKE; POLHILL, 1981; KUNIYOSHI, 1983; PARRA, 1984). O conhecimento desse conjunto de variações morfológicas é fundamental para que se possam realizar investigações sobre sucessão e regeneração em ecossistemas florestais (SILVA et al., 1988), bem como sobre a produção de mudas para diversas finalidades.

Segundo Hickey (1979), a arquitetura das folhas é pouco explorada, embora seja importante por revelar sua histologia, função, origem e homologia, por meio da análise do padrão de nervação, da configuração da borda, do ápice e margem, da forma foliar e da posição de glândulas. Diferenças no padrão de venação foliar permitiram a separação de espécies de Eugenia (COSTA et al., 1995; CARDOSO; SAJO, 2004), porém essa característica mostrou-se bastante uniforme nas subtribos de Myrtaceae (CARDOSO; SAJO, 2006) ou para diversas famílias de florestas subtropicais de Taiwan (LIU; HSIEH, 1997). Assim, essa característica não deve ser utilizada para separar subtribos ou famílias, mas para auxiliar na identificação de espécies.

De acordo com Moreira e Oliveira (2006), os limbos de eófilos tendem para uma maior complexidade estrutural, quando comparados aos limbos cotiledonares, o que é atribuído à sua efemeridade e função de provisão de reservas de tempo relativamente curto de estocagem. Apesar da importância de tais estruturas para o estabelecimento das plantas, poucos são os estudos morfológicos que enfocam o desenvolvimento foliar das plântulas (MOREIRA; OLIVEIRA, 2006; CAVICHIOLO, 2006). Nesse contexto, o presente trabalho investigou comparativamente a morfologia dos limbos cotiledonares e eofilares, e o desenvolvimento inicial das folhas, com o objetivo de caracterizar as diversas fases de desenvolvimento das plântulas de cinco espécies arbóreas representativas da Floresta Estacional Semidecidual, a fim de facilitar sua identificação em campo.

\section{MATERIAIS E MÉTODOS}

\section{As espécies estudadas}

Foram utilizadas sementes de espécies arbóreas, dos estágios sucessionais pioneiro e secundário tardio, indicadas para recomposição de ambientes ripários em Floresta Estacional Semidecidual (MARTINS, 2005): Parapiptadenia rigida (Benth.) Brenan (angico-vermelho), Cedrela fissilis Vell. (cedro-rosa), Astronium graveolens Jacq. (guaritá), Tabebuia avellanedae Lorentz ex Griseb (ipê-roxo) e Gallesia integrifolia (Spreng.) Harms (pau-d'alho). A nomenclatura adotada esteve de acordo com o Angiosperm Phylogeny Group (APG) III (2009) e foi conferida no site Tropicos.org (2011). As espécies selecionadas são representativas de Floresta Estacional Semidecidual, ocorrendo em diversos tipos de fragmentos florestais (LORENZI, 1992; CORVELLO et al., 1999; CARVALHO et al., 2006; PEREIRA et al., 2008). Além da importância ecológica na regeneração florestal natural, as cinco espécies escolhidas podem ser utilizadas em plantios mistos com vistas à restauração de áreas degradadas $(P$. rigida e $C$. fissilis, T. avellanedae e G. integrifolia), ou para paisagismo (A. graveolens) (LORENZI, 1992).

\section{Produção de mudas e coleta de material}

As sementes foram obtidas na Companhia Energética de São Paulo (CESP), Porto Primavera, São Paulo (SP). Cem (100) sementes de cada espécie foram colocadas para germinar em placas de Petri (10 sementes por placa) com papel de filtro umedecido em água destilada. A metade das sementes 
permaneceu sob lâmpadas fluorescentes (iluminação contínua) e as demais em câmara escura. Independentemente do tratamento aplicado, após a emergência da radícula as sementes foram transferidas para recipientes plásticos com substrato preparado pela mistura de solo fértil e húmus de origem vegetal. Conforme sugerido por Roderjan (1983), o termo "plântula" foi utilizado quando as plantas apresentaram os cotilédones e o primeiro par de eófilos ou protófilos desenvolvidos, e o termo "muda" é empregado para o estágio em que os protófilos atingiram um desenvolvimento diferenciado ao dos protófilos de $1^{\text {a }}$ ordem (metáfilo). O plantio foi realizado no viveiro de mudas da Universidade Estadual de Maringá (UEM), Maringá, Paraná, Brasil, sendo as plântulas e mudas irrigadas diariamente. O acompanhamento das mesmas foi feito até o desenvolvimento de folhas similares às da fase adulta (entre 8 e $10 \mathrm{~cm}$ de altura), por um período de 4 meses. A cada diferenciação foliar, foram retiradas cinco plântulas inteiras, as quais, após a lavagem, foram fixadas em FAA 50\% (JOHANSEN, 1940) e posteriormente em álcool 70\%. Para análise da nervação, as folhas e folíolos foram diafanizados pela técnica de Fuchs (1963), a qual consiste em clarificar órgãos vegetais por meio de processo químico. As plântulas fixadas foram lavadas com água destilada e colocadas em solução de NAOH a 5\% por uma hora e, depois de lavadas novamente com água destilada, foram transferidas para solução de hipoclorito a 33\%. O tempo de permanência nessa solução dependeu do tipo e espessura do protofilo. Quando transparentes, as folhas foram lavadas em água destilada, em seguida coradas com safranina aquosa $1 \%$ e passadas por uma bateria de álcool $\left(30^{\circ}, 50^{\circ}, 70^{\circ}, 90^{\circ}, 100^{\circ}\right)$ e xilol-álcool $(1: 3,1: 1,3: 1$ e xilol puro), sendo a seguir montadas como lâminas permanentes com Permount ${ }^{\circledR}$ e desenhadas com auxílio de câmara-clara. Para a análise e descrição dos padrões de venação foliar, foram utilizados os tipos básicos definidos por Ash et al. (1999). Para as descrições morfológicas, utilizou-se a nomenclatura adotada por Souza (2003). As medidas de raízes foram realizadas nos indivíduos desenhados.

\section{RESULTADOS E DISCUSSÃO}

As cinco espécies analisadas mostraram-se indiferentes à luz, germinando tanto na presença como na ausência da mesma. Barros et al. (2005) não encontraram efeito da luz e da temperatura sobre a germinação de G. integrifolia. As porcentagens de germinação de todas as espécies analisadas foram altas, atingindo aproximadamente $100 \%$ em qualquer dos dois tratamentos, com exceção de $G$. integrifolia, que só germinou quando semeada diretamente no substrato próprio para as mudas, embora as sementes dessa espécie não possuam dormência física ou fisiológica (CAPELANES, 1989; DURIGAN et al., 1997; CARVALHO, 2003; BARROS et al., 2005). Barros et al. (2005) sugeriram que as sementes de G. integrifolia germinam melhor em substratos com menor teor de umidade, de modo que, na situação experimental imposta no presente estudo, a água acumulada na placa de Petri pode ter sido o fator responsável pelo fracasso do processo germinativo. De acordo com Amaral (1986), o substrato deve permanecer suficientemente umedecido durante tal processo, mas as sementes não devem ser envolvidas por uma película de água, já que isso pode restringir sua respiração. A quantidade de água necessária para a embebição das sementes geralmente é pequena, e a difusão da água ocorre em um gradiente de energia no sentido de alto para baixo potencial hídrico (BEWLEY; BLACK, 1994).

A germinação das cinco espécies enquadrou-se no tipo epígea e fanerocotiledonar, conforme descrições de Souza (2003), mas também se enquadraram no tipo fanero-epigeofoliáceo, descrito por Miquel (1987). Os cotilédones mostraram-se persistentes, foliáceos, peciolados (Figura 1-5), com maior desenvolvimento do hipocótilo. Em C. fissilis, o pecíolo e o hipocótilo apresentaram-se pilosos, enquanto que em $T$. avellanedae, A. graveolens e G. integrifolia, o hipocótilo e epicótilo foram glabros; já em $P$. rigida, o hipocótilo mostrou-se piloso, embora o epicótilo fosse glabro.

As plântulas das cinco espécies analisadas mostraram-se com eófilos de filotaxia oposta, mas morfologicamente distintas, desde suas folhas cotiledonares até os eófilos e metáfilos (Figura 1-5). A duração das fases de plântula e muda variou com a espécie, com valores máximos de 64 e 110 dias (Tabela 1).

Parapiptadenia rigida (Figura 1) aos 36 dias ainda apresentava cotilédones reniformes com ápice retuso, base sagitada a hastada e borda íntegra (Figura 1A-1C). Aos 77 dias de plantio, os metáfilos apresentavam-se compostos, paribipinados com tamanho variando entre 2 e $3 \mathrm{~cm}$ e folíolos de $1 \mathrm{~cm}$ de comprimento. Os folíolos apresentaram-se lanceolados, com borda íntegra, ápice agudo e base obtusa (Figura 1D). 
Tabela 1. Tempo (dias) necessário para a germinação, início da fase de plântula e formação de muda das espécies estudadas.

Table 1. Time (days) required for germination, early seedling stage and sapling stage for the focused species.

\begin{tabular}{lccc}
\hline Espécie & Germinação & Plântula & Muda \\
\hline A. graveolens & 5 & 25 & 42 \\
C. fissilis & 5 & 48 & 110 \\
G. integrifolia & 19 & 64 & 110 \\
P. rigida & 5 & 36 & 77 \\
T. avellanedae & 5 & 38 & 67 \\
\hline
\end{tabular}

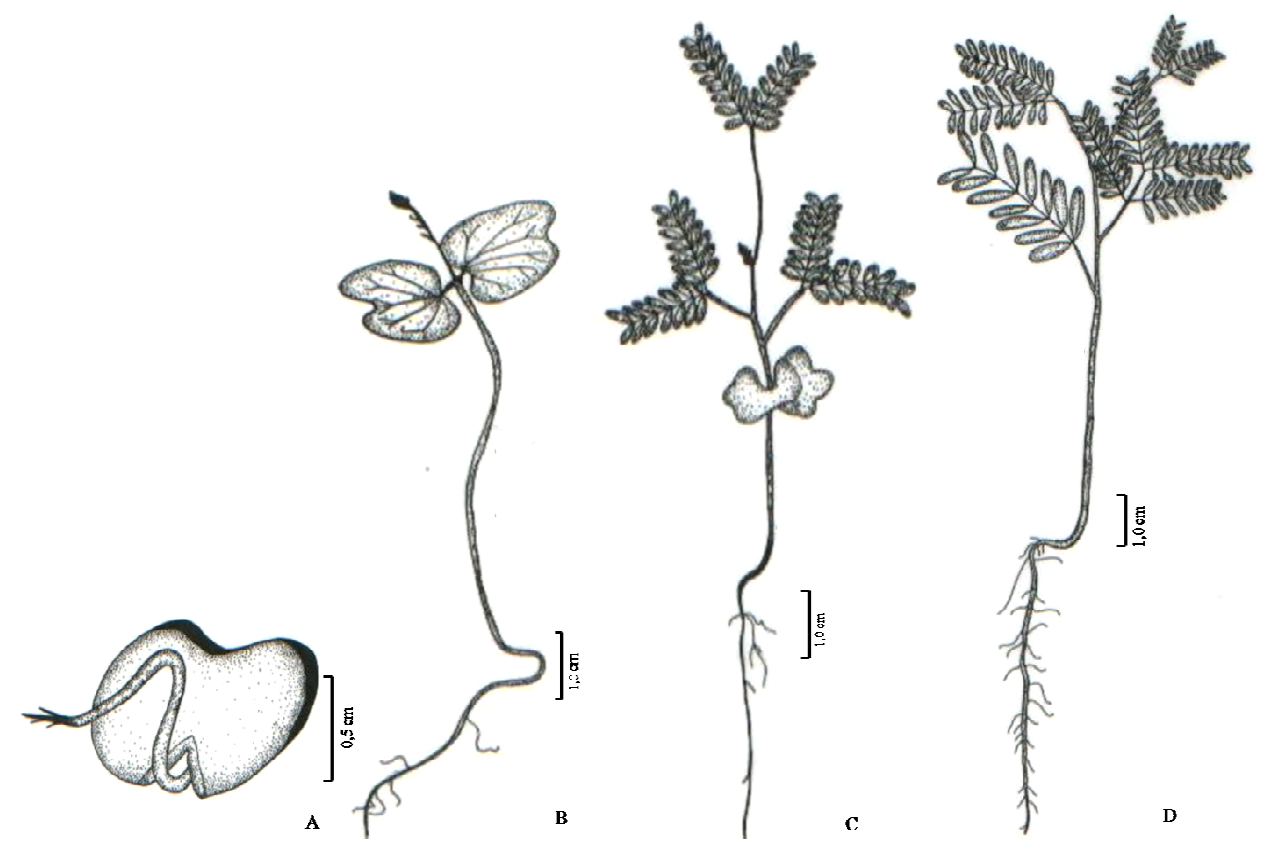

Figura 1. Parapiptadenia rigida aos: A: 5 dias; B: 15 dias; C: 36 dia; D: 77 dias.

Figure 1. Parapiptadenia rigida at: A: 5 days; B: 15 days; C: 36 days; D: 77 days.

Cedrela fissilis (Figura 2) aos 48 dias de plantio apresentava eófilos compostos, trifoliados, de tamanhos desiguais, ápice agudo, base cuneada a obtusa, borda íntegra nos folíolos inferiores e o maior com borda crenulada, e ainda com os cotilédones oblongos, ápice e base obtusos (Figura 2C). Aos 110 dias, as mudas apresentaram folhas compostas, imparipinadas, com cerca de $6 \mathrm{~cm}$ de comprimento e cada folíolo com $2 \mathrm{~cm}$, lanceolados, com ápice cuneado, base obtusa e margem serrilhada irregular (Figura 2D). Segundo Lorenzi (1992), no indivíduo adulto, as folhas chegam a atingir de 60 a $100 \mathrm{~cm}$ de comprimento, com folíolos de 8 a $14 \mathrm{~cm}$ de comprimento.

Astronium graveolens (Figura 3) aos 15 dias de plantio possuía cotilédones de $1 \mathrm{~cm}$ de comprimento, reniformes, com ápice retuso e base sagitada a hastada (Figura 3B). Aos 45 dias, suas folhas se mostravam pecioladas $(3-4 \mathrm{~cm})$, compostas, imparipinadas; com folíolos de margem serrilhada, espaçados irregularmente, de tamanhos desiguais, forma ovada, ápice acuminado e base oblíqua e odor característico de alho (Figura 3D). No indivíduo adulto, as folhas possuem 4 a 7 pares de folíolos, os maiores de 6 a $8 \mathrm{~cm}$ de comprimento e os menores, 3 a $4 \mathrm{~cm}$ (LORENZI, 1992).

Tabebuia avellanedae (Figura 4) após 15 dias de plantio apresentava cotilédones reniformes, íntegros, com ápice retuso e base auriculada a hastada (Figura 4B). Após 38 dias, as plântulas apresentaram eófilos assimétricos, com ápice retuso e base cordada e borda serreada (Figura 4C). Aos 67 
dias, os metáfilos apresentaram-se compostos, imparipinados, com folíolos quase glabros, de 5 a $7 \mathrm{~cm}$ de comprimento por 3 a $4 \mathrm{~cm}$ de largura, com formato ovado, ápice agudo, base arredondada e margem serreada (Figura 4D).

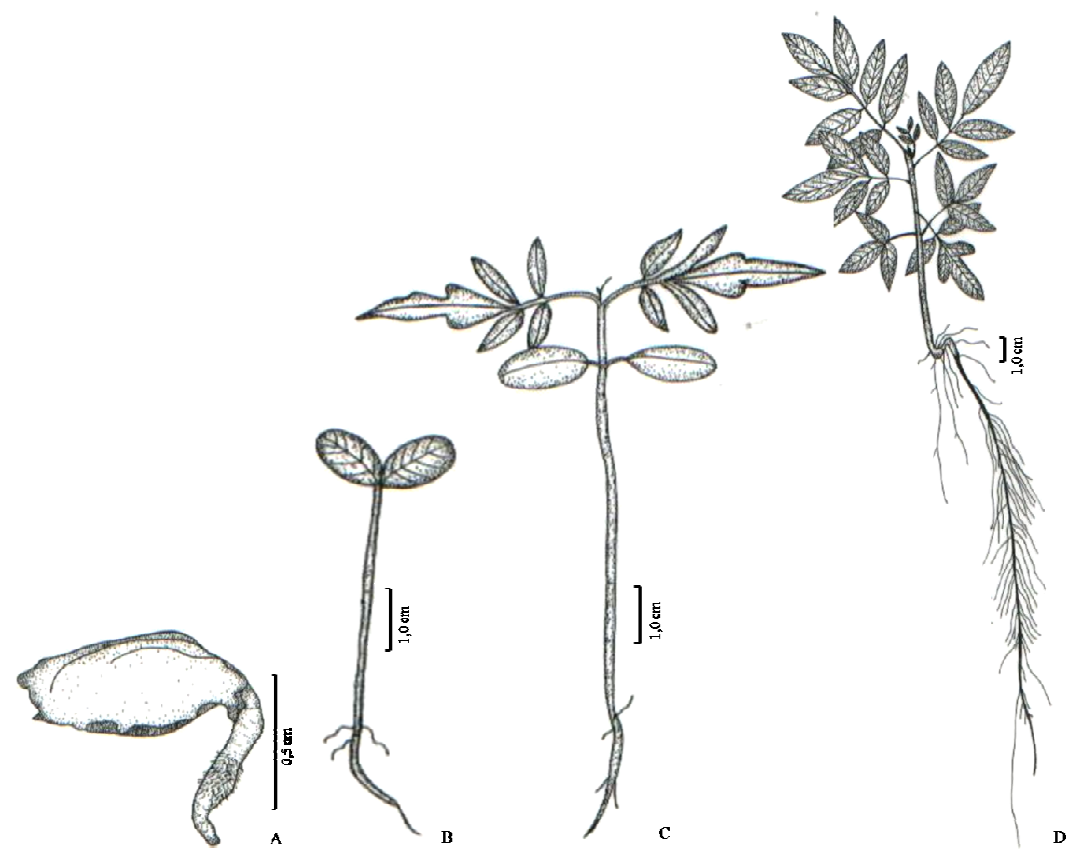

Figura 2. Cedrela fissilis aos: A: 5 dias; B: 20 dias; C: 48 dias; D: 110 dias. Figure 2. Cedrela fissilis at: A: 5 days; B: 20 days; C: 48 days; D: 110 days.

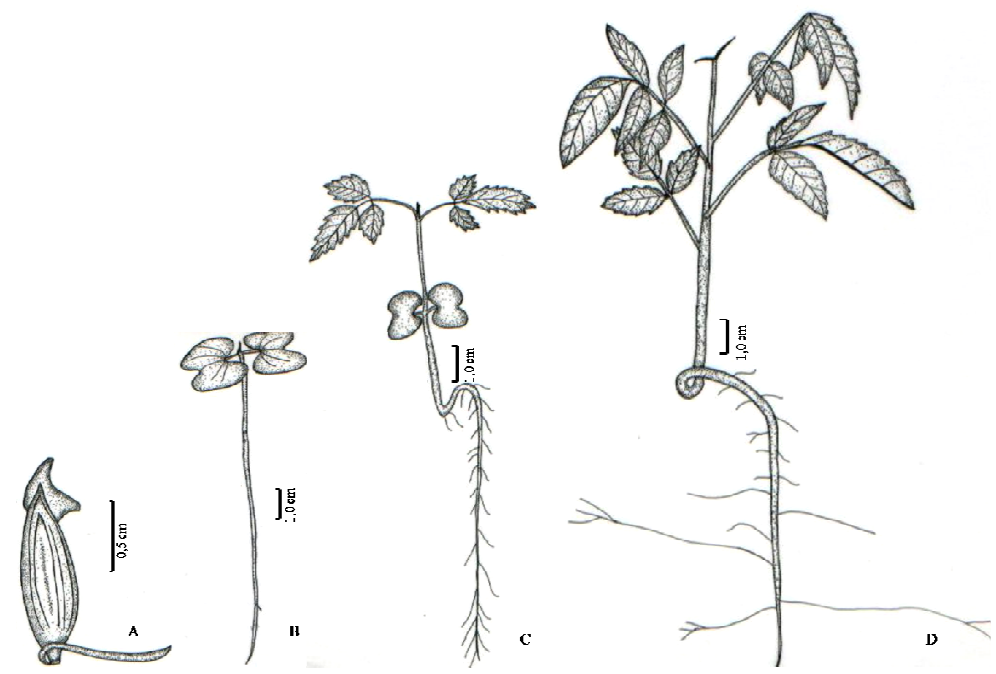

Figura 3. Astronium graveolens aos: A: 5 dias; B: 15 dias; C: 25 dias; D: 42 dias.

Figure 3. Astronium graveolens at: A: 5 days; B: 15 days; C: 25 days; D: 42 days.

Gallesia integrifólia (Figura 5) aos 48 dias após a semeadura apresentava cotilédones coriáceos, com $3 \mathrm{~cm}$ de largura e $3 \mathrm{~cm}$ de comprimento (Figura 5B), enquanto que aos 110 dias as folhas eram simples, glabras, coriáceas, de 4 a $6 \mathrm{~cm}$ de comprimento, lanceoladas, com ápice agudo, base cuneada e margem íntegra (Figura 5D). 


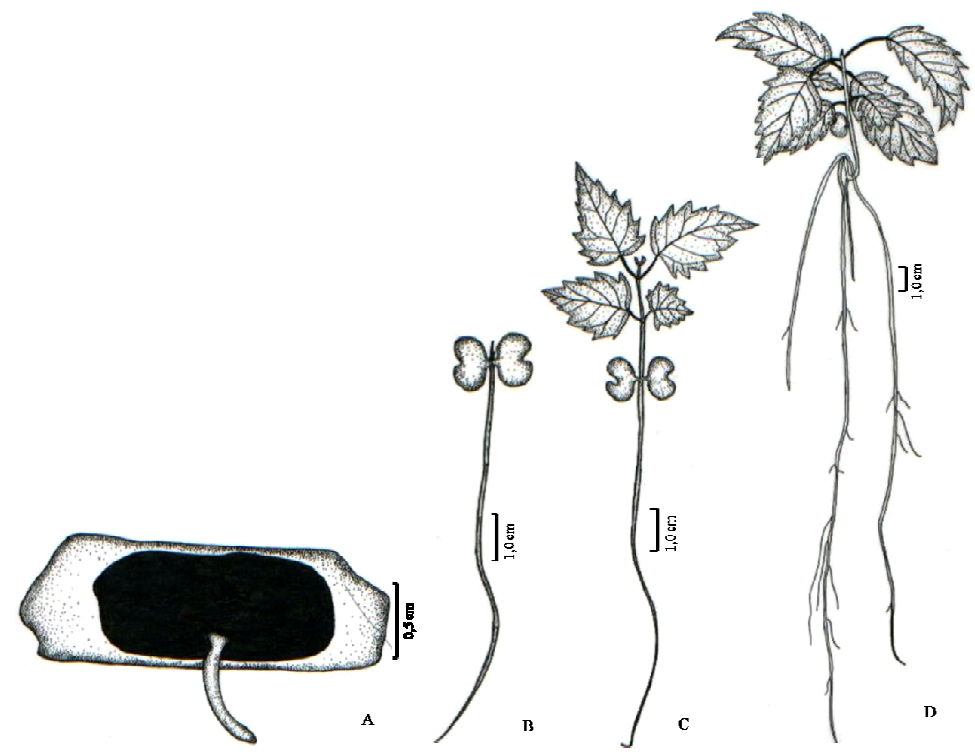

Figura 4. Tabebuia avellanedae aos: A: 5 dias; B: 15 dias; C: 38 dias; D: 67 dias.

Figure 4. Tabebuia avellanedae at: A: 5 days; B: 15 days; C: 38 days; D: 67 days.

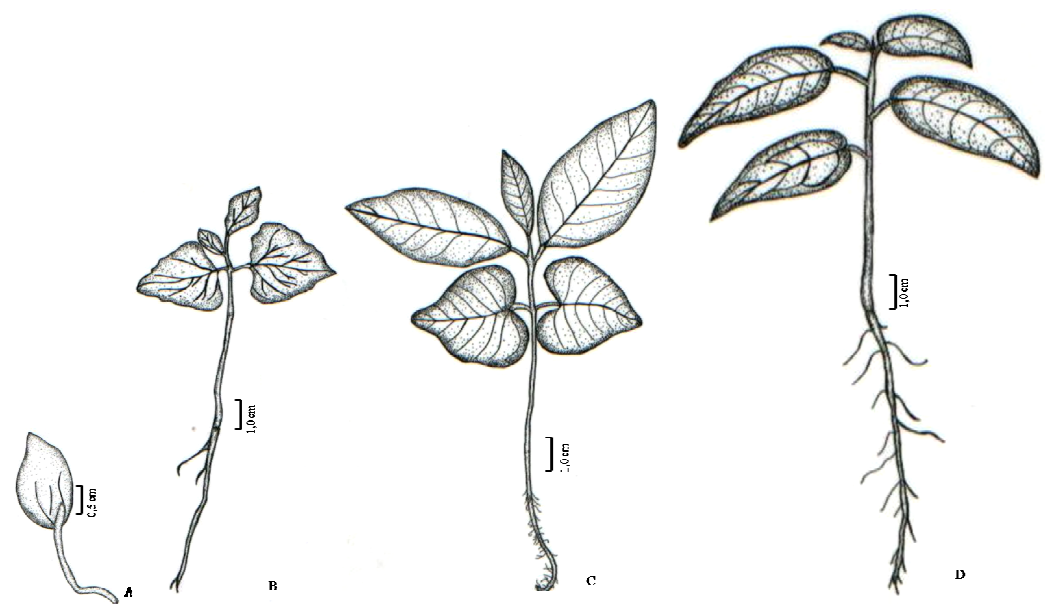

Figura 5. Gallesia integrifolia aos: A: 19 dias; B: 48 dias; C: 64 dias; D: 110 dias. Figure 5. Gallesia integrifolia at: A: 19 days; B: 48 days; C: 64 days; D: 110 days.

Os cotilédones de $P$. rigida, A. graveolens e T. avellanedae possuem nervação palminérvea com padrão acródromo em $P$. rigida e T. avellanedae (Figura 6A, 6C), e em A. graveolens (Figura 6F), padrão misto, acródromo-broquidódromo. Os cotilédones de C. fissilis e G. integrifolia apresentam nervação peninérvea, sendo o primeiro com padrão acródromo (Figura $6 \mathrm{H}$ ) e o outro camptódromo-broquidódromo (Figura 6K).

O eófilo de T. avellanedae possui venação peninérvea, padrão acródromo (Figura 6I), e o de $C$. fissilis, peninérvea, camptódromo-broquidódromo (Figura 6D).

A nervura dos folíolos de $P$. rigida apresenta-se com padrão reticuladódromo (Figura 6B), e a dos metáfilos de $C$. fissilis e T. avellanedae, peninérvea com padrão acródromo (Figura $6 \mathrm{E}, 6 \mathrm{~J}$ ), enquanto que em A. graveolens e G. integrifolia mostra-se peninérvea, camptódromo-broquidódromo (Figura 6G, 6L).

As nervuras terciárias foram observadas nos cotilédones de $P$. rigida, A. graveolens e $T$. avellanedae, sendo todas ramificadas admediais (Figura 6A, 6C, 6H). No eófilo do T. avellanedae, a nervura terciária apresenta-se reticulada ao acaso (Figura 6I). Já nos metáfilos, em sua maioria, a nervura 
terciária é ramificada e admedial (Figura 6E, 6G, 6J), com exceção de G. integrifolia, em que a nervura é reticulada ortogonal (Figura $6 \mathrm{~L}$ ).

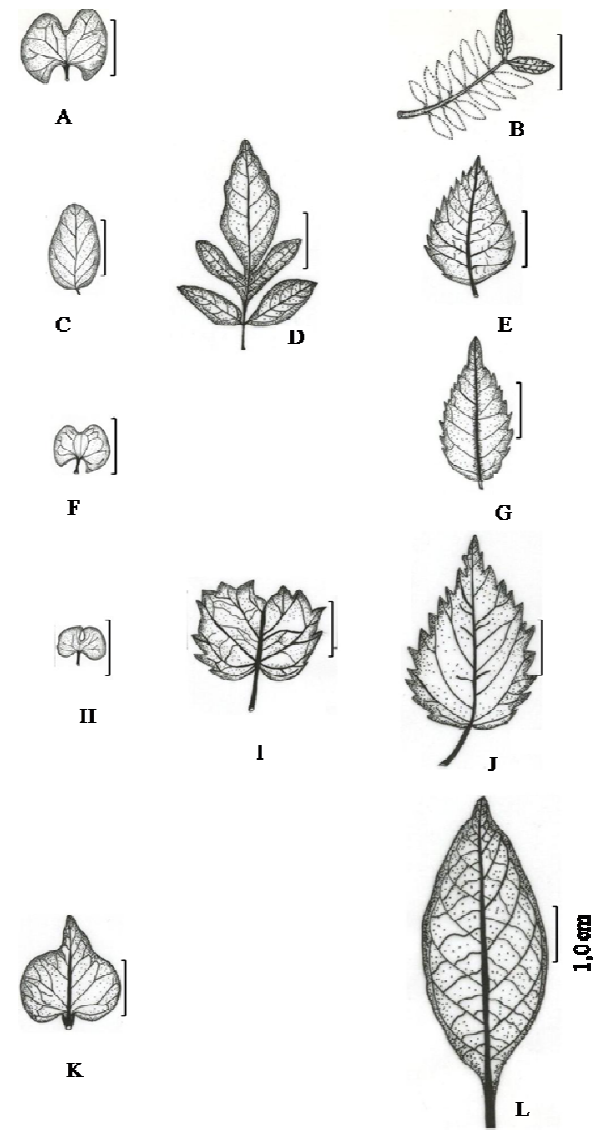

Figura 6. Cotilédones, eófilos e metáfilos com escala similar de tamanho $(1 \mathrm{~cm})$. Nas plântulas e mudas com folhas compostas estão representados somente os maiores folíolos. A-B: Parapiptadenia rigida; C-D: Cedrela fissilis; F-G: Astronium graveolens; H-J: Tabebuia avellanedae; K-L: Gallesia integrifolia.

Figure 6. Cotyledons, eophylls and metaphylls with similar range of size $(1.0 \mathrm{~cm})$. In seedlings with compounded leaves only the largest leaflet is represented. A-B - Parapiptodenia rigida; C-D Cedrela fissilis; F-G: Astronium graveolens; H-J:Tabebuia avellanedae; K-L: Gallesia integrifolia.

Nas cinco espécies analisadas, houve grande produção de raízes pivotantes, alcançando $25,6 \mathrm{~cm}$ em T. avellanedae aos 67 dias de plantio (Figura 4D), 19,0 cm de comprimento em $C$. fissilis aos 110 dias (Figura 2D), 8,12 cm em A. graveolens aos 42 dias (Figura 3D), 7,3 cm em G. integrifolia aos 110 dias (Figura 5D) e 6,14 cm em P. rigida aos 77 dias (Figura 1D). Em virtude disso, o plantio dessas espécies deve ser realizado em recipientes profundos, para não comprometer o desenvolvimento das mudas. A produção, via semeadura direta, nos recipientes é aconselhada em virtude da facilidade de trabalho e redução de operações e de doenças no viveiro (MARTINS et al., 2004).

Desde as fases iniciais de desenvolvimento, foi possível observar diferenças morfológicas entre as espécies analisadas, tanto no formato quanto na venação dos cotilédones (Tabela 2), indicando a importância da morfologia foliar como mais uma ferramenta para a identificação e preservação das espécies em campo, facilitando a execução de sistemas de recuperação ambiental por regeneração natural. Essa identificação em campo evitaria esforços na produção e no plantio de mudas em áreas com banco ativo de sementes, onde as plântulas podem ser facilmente reconhecidas e, consequentemente, utilizadas. Além disso, considerando as altas taxas de germinação encontradas, tanto neste estudo quanto em outros 
com as mesmas espécies (CORVELLO et al., 1999; BARROS et al., 2005), a produção de mudas em casa de vegetação pode também ser conduzida com maior eficiência e economia.

Tabela 2. Características morfológicas (formato/venação) dos protófilos que permitem a separação das espécies estudadas.

Table 2. Morphological characteristics (shape/venation) of protophylls that allow separation of the studied species.

\begin{tabular}{lccc}
\hline Espécie & Cotilédones & Eófilo & Metáfilo \\
\hline A. graveolens & reniformes/palminérvea & - & compostos, imparipinados \\
C. fissilis & oblongos/ peninérvea & compostos, trifoliados & compostos, imparipinados \\
G. integrifólia & coriáceos/ peninérvea & - & simples, lanceolados \\
P. rígida & reniformes/ palminérvea & - & compostos, paribipinados \\
T. avellanedae & reniforme/ palminérvea & assimétricos & compostos, imparipinados \\
\hline
\end{tabular}

Diante da realidade de que imensas áreas de Floresta Estacional Semidecidual já foram desmatadas, necessitando urgentemente ser recuperadas (BARBOSA et al., 2003), diversas estratégias de recomposição devem ser adotadas, de acordo com o grau de degradação da área, da presença de matrizes e de banco de sementes no solo (MARTINS et al., 2005). A identificação de plântulas das espécies nativas, no campo, se mostra como uma importante ação a ser implantada em áreas de plantios heterogêneos, recomendados para preservar a diversidade de fragmentos florestais (LORENZI, 1992; BARBOSA et al., 2003). Nesse sentido, os caracteres morfológicos foliares, apontados no presente estudo, serão de grande valia, contribuindo para orientar essas atividades e seu sucesso.

\section{AGRADECIMENTO}

Agrademos à Universidade Estadual de Maringá (UEM), pela estrutura cedida. À Dra. Maria Auxiliadora Milaneze-Gutierrez, agradecemos pelo auxílio na descrição das características morfológicas das plântulas; à Elimaida Cortez e Gislaine Angélica Rodrigues Silva, pelo auxílio na execução do projeto e à Wanda Laura Lopes pelo cuidado com as plântulas e mudas.

\section{CONCLUSÃO}

- A análise das espécies arbóreas Astronium graveolens, Cedrela fissilis, Gallesia integrifolia, Parapiptadenia rigida e Tabebuia avellanedae permite concluir que as plântulas apresentam características foliares distintas desde suas folhas cotiledonares até os eófilos e metáfilos, permitindo, desta forma, sua identificação na comunidade vegetal.

\section{REFERÊNCIAS}

AMARAL, D. M. I. Padronização de testes em laboratório com sementes florestais. In: SIMPÓSIO BRASILEIRO SOBRE TECNOLOGIA DE SEMENTES FLORESTAIS, 1, 1986. (Aguiar, I. B., coord.). Abrates, Brasília, Anais do... Brasília, p. 267 - 283, 1986.

AMO-RODRIGUES, S. Clave para plántulas y estados juveniles de espécies primárias de una selva alta perinnifolia en Veracruz, México. Biotropica, St. Louis, v. 4, n. 2, p. 58 - 108, 1979.

APG III. An update of the Angiosperm Phylogeny Group classification for the orders and families of flowering plants: APG III. Botanical Journal of the Linnean Society, London, v. 161, p. 128 - 131, 2009.

ASH, A.; ELLIS, B.; HICKEY, L. J.; JOHNSON, K.; WILF, P.; WING, S. Manual of leaf Architecture morphological description and categorization of dicotyledonous and net-veined monocotyledonous angiosperms by Leaf Architecture Working Group. Smithsonian Institution, Washington. Disponível em <http://www.yale.edu/peabody/collections/pb/MLAintro.pdf>. Acesso em: 10/05/2011.

BARBOSA, L. M.; BARBOSA, J. M.; BARBOSA, K. C.; POTOMATI, A.; MARTINS, S. E.; ASPERTI, L. M.; MELO, A. C. G.; CARRASCO, P. G.; CASTANHEIRA, S. A.; PILIACKAS, J. M. 
Recuperação florestal com espécies nativas no estado de São Paulo: Pesquisas Apontam Mudanças Necessárias. Florestar Estatístico, São Paulo, v. 6, n. 14, p. 28 - 34, 2003.

BARROS, S. S. U.; SILVA, A.; AGUIAR, I. Germinação de sementes de Gallesia integrifolia (Spreng.) Harms (pau-d'alho) sob diferentes condições de temperatura, luz e umidade do substrato. Revista Brasileira de Botânica, São Paulo, v. 28, n. 4, p. 727 - 733, 2005.

BELTRATI, C. M. Morfologia e anatomia das sementes e plântulas de Eucalyptus maidenni. Turrialba. San José, v. 28, n. 3, p. 209 - 214, 1978.

BEWLEY, J. D.; BLACK, M. Seeds: physiology of development and germination. 2. ed. Plenum Press, New York, 1994. 445 p.

CAPELANES, T. M. C. Tecnologia de sementes florestais na Companhia Energética de São Paulo. In: $2^{\circ}$ Simpósio brasileiro sobre tecnologia de sementes florestais. Anais... São Paulo, p. 49 - 57, 1989.

CARDOSO, C. M. V.; SAJO, M. G. Vascularização foliar e a identificação de espécies de Eugenia L. (Myrtaceae) da bacia hidrográfica do Rio Tibagi, PR. Revista Brasileira de Botânica, São Paulo, v. 27, n. 1, p. 47 - 54, 2004.

CARVALHO, F. A.; NASCIMENTO, M. T.; BRAGA, J. M. A. Composição e riqueza florística do componente arbóreo da Floresta Atlântica Submontana na região de Imbaú, Município de Silva Jardim, RJ. Acta Botanica Brasílica, São Paulo, v. 20, n. 3, p. 727 - 740, 2006.

CARVALHO, P. E. R. Espécies arbóreas brasileiras. v. 1. EMBRAPA - Informação Tecnológica, Brasília. 2003. v. 1, 1039 p.

CAVICHIOLO, L. E. Aspectos morfológicos e ecológicos dos principais tipos morfofuncionais de plântulas ocorrentes na ilha do Mel, PR. 71 f. Dissertação (Mestrado em Botânica) - Universidade Federal do Paraná, Curitiba, 2006.

CORVELLO, W. B. V.; VILLELA, F. A.; NEDEL, J. L.; PESKE, S. T. Época de colheita e armazenamento de sementes de cedro (Cedrela fissilis Vell.). Revista Brasileira de Sementes, São Paulo, v. 21, n. 2, p. 28 - 34, 1999.

COSTA, C. G.; MACHADO, R. D.; FONTENELlE, J. B. Sistema vascular em folhas de Eugenia L. (Myrtaceae). Boletim do Herbarium Bradeanum, Rio de Janeiro, v. 6, n. 42, p. 345 - 356, 1995.

DUKE, J. A.; POLHILL, R. M. Seedlings of Leguminosae. In: POLHILL, R. M.; RAVEN, A. G. Advances in Legume Systamatics, Kew: Crow Copringht, p. 941 - 949, 1981.

DURIGAN, G.; FIGLIOLIA, M. B.; KAWABATA, M.; GARRIDO, M. A. O.; BAITELLO, J. B. Sementes e mudas de árvores tropicais. São Paulo: Páginas \& Letras, 1997. 65 p.

FUCHS, C. H. Fuchs in staining with $\mathrm{NaOH}$ clearing for lignified of whole plants organs. Stain Technology, Baltimore, v. 38, n. 3, p. 141 - 144, 1963.

GARWOOD, N. C. Functional morphology of tropical tree seedlings. In: The ecology of tropical forest tree seedlings. (Swaine, M.D., Ed.). Paris: UNESCO/The Parthenon Publishing Group, 1996, p. 59 - 129.

GÓMEZ-POMPA, A.; WIECHERS, B. L. Regeneration de los ecosistemas tropicales y subtropicales. In: GÓMEZ-POMPA, A.; VÁZQUEZ-YANES, C.; AMO RODRÍGUEZ, S. Regeneration de selvas. Mexico: Continental. 1976, p. 11 - 30.

HICKEY, L. J. A revised classification of architecture of dicotyledonous leaves. In: METCALFE, C.R., CHALK, L. (eds.). Anatomy of Dicotyledons. 2. ed. Oxford: Clarendon Press, 1979, v. 1, p. 25 - 39.

JOHANSEN, D. A. Plant Microtechnique. McGraw-Hill Book, New York, 1940. 790 p.

KUNIYOSHI, Y. S. Morfologia da semente e da germinação de 25 espécies arbóreas de uma floresta com araucária. 233 f. Dissertação (Mestrado em Silvicultura) - Universidade Federal do Paraná, Curitiba, 1983. 
LIU, S. P.; HSIEH, C. F. Seedling morphology of some woody species in subtropical rain forest of Southern Taiwan, Taiwania, Taipei, v. 42, n. 3, p. 207 - 238, 1997.

LORENZI, H. Árvores brasileiras: manual de identificação e cultivo de plantas arbóreas nativas do Brasil. Nova Odessa, São Paulo: Plantarum, 1992, 351 p.

MARTINS, S. S.; SILVA, I. C.; BORTOLO, L.; NEPOMUCENO, A. N. Produção de mudas de espécies florestais nos viveiros do Instituto Ambiental do Paraná. Maringá: Clichetec, 2004, 192 p.

MARTINS, S. S. Recomposição de matas ciliares no Estado do Paraná. 2. ed. Rev. e atual. Maringá: Clichetec, 2005, $32 \mathrm{p}$.

MIQUEL, S. Morphologie fonctionnelle de plantules d'espèces forestières du Gabon. Buletin du Muséum National d'Histoire Naturelle, Paris, v. 1, p. 101 - 121, 1987.

MORAES, P. L. R.; PAOLI, A. A. S. Morfologia e estabelecimento de plântulas de Cryptocarya moschata Nees, Ocotea catharinensis Mez e Endlicheria paniculata (Spreng.) MacBride - Lauraceae. Revista Brasileira de Botânica, São Paulo, v. 22, n. 2, p. 287 - 295, 1999.

MOREIRA, I. R.; OLIVEIRA, D. M. T. Anatomia comparada dos limbos cotiledonares e eofilares de dez espécies de Caesalpinioideae (Fabaceae). Revista Brasileira de Botânica, São Paulo, v. 29, n. 2, p. 193 207, 2006.

MOURÃO, K. S. M.; DIAS-PINTO, D.; SOUZA, L. A. de; MOSCHETA, I. S. Morfo-anatomia da plântula e do tirodendro de Trichilia catigua A. Juss., T. elegans A. Juss. e T. pallida Sw. (Meliaceae). Acta Scientiarum, Maringá, v. 24, n. 2, p. 601 - 610, 2002.

PALÁCIOS, R. A.; BRAVO, L. D. Estúdio morfológico de las semillas de Prosopis II: algumas espécies norte-americanas y neotropicales. Darwiniana, New York, v. 199, n. 2/4, p. 257 - 372, 1975.

PARRA, R. Estúdio de la morfologia externa de plantulas de Calliandra gracilis, Mimosa albida, Mimosa arenosa, Mimosa camporum y Mimosa tenuiflora. Revista de la Facultad de Agronomia. Maracay, v. 13, n. 1 - 4, p. 311 - 350, 1984.

PEREIRA, T. S.; COSTA, M. L. M. N.; MORAES, L. F. D.; LUCHIARI, C. Fenologia de espécies arbóreas em Floresta Attântica da reserva biológica de Poço das Antas, Rio de Janeiro, Brasil. Iheringia, Série Botânica, Porto Alegre, v. 63, n. 2, p. 329 - 339, 2008.

RESSEL, K.; GUILHERME, F. A. G.; SCHIAVINI, I. Ecologia morfofuncional de plântulas de espécies arbóreas da Estação Ecológica do Panga, Uberlândia, Minas Gerais. Revista Brasileira de Botânica, São Paulo, v. 27, n. 2, p. 311 - 323, 2004.

RODERJAN, C. V. Morfologia do estágio juvenil de 24 espécies arbóreas de uma floresta com araucária. 148 f. Dissertação (Mestrado em Engenharia Florestal) - Universidade Federal do Paraná, Curitiba, 1983.

SILVA, M.; GOLDMAN, G.; MAGALHÃES, F.; MOREIRA, F. Germinação natural de dez espécies arbóreas da Amazônia. Acta Amazônica, Manaus, v. 18, n. 1 - 2, p. 9 - 26, 1988.

SOUZA, L. A. Morfologia e anatomia vegetal (célula, tecidos, órgãos e plântula). Ponta Grossa: Editora da Universidade Estadual de Ponta Grossa, 2003, 258 p.

SOUZA, L. A.; MOSCHETA, I. S. Morfo-anatomia do fruto e da plântula de Aspidosperma polyneuron M. Arg. (Apocynaceae). Revista Brasileira de Biologia, São Carlos, v. 52, n. 3, p. 439 - 447, 1992.

SOUZA, L. A.; OLIVEIRA, J. H. G. Morfologia e anatomia das plântulas de Tabebuia avellanedae Lor. Ex Griseb e T. chrysotricha (Mart. ex DC.) Standl. (Bignoniaceae). Acta Scientiarum, Biological Sciences, Maringá, v. 26, p. 217 - 226. 2004.

TROPICOS.ORG. Missouri Botanical Garden. 2011. Disponível em: 〈http://www.tropicos.org>. Acesso em: 21/07/2011. São Paulo. 